\title{
A new peculiar species of Anaclileia Meunier (Diptera: Mycetophilidae) from Georgia, Transcaucasia
}

\author{
Olavi Kurina
}

Kurina, O. 2018: A new peculiar species of Anaclileia Meunier (Diptera: Mycetophilidae) from Georgia, Transcaucasia. - Entomol. Fennica 29: 153-160.

A new fungus gnat species, Anaclileia adjarica sp. n. (Diptera: Mycetophilidae) from Georgia is described, illustrated and discussed. The species represents the first record of the genus from Georgia as well as from whole Caucasus region. The new species is distinguished by the peculiar and unique structure of the male terminalia, especially that of the tergite 9 which includes posterolateral megasetae and a heart-shaped aggregation of small spines. The possible distributional range of the new species is discussed.

O. Kurina, Institute of Agricultural and Environmental Sciences, Estonian University of Life Sciences, Kreutzwaldi st 5 D, 51014 Tartu, Estonia. E-mail: olavi.kurina@emu.ee

Received 23 October 2017, accepted 8 January 2018

\section{Introduction}

The fungus gnat genus Anaclileia Meunier, 1904 belongs to the subfamily Sciophilinae of Mycetophilidae, sharing the basally obsolete vein $\mathrm{M}_{1}$ with two other genera-Polylepta Winnertz, 1863 and Neuratelia Rondani, 1856 (e.g. Søli et al. 2000), and is distinguished from these genera by other details of the wing venation. According to the phylogenetic analysis based on morphological characters by Borkent and Wheeler (2013), Anaclileia is supported by five homoplasious character states and is placed as the sister group to the remaining members of tribe Sciophilini. There are no molecular analyses that include Anaclileia (see e.g. Rindal et al. 2009, Ševčík et al. 2016), probably because these gnats are quite rarely encountered in samples and there is no fresh material available for such studies.

Twelve species of Anaclileia are known so far, eight of which are extant and four have been described from fossils (Zaitzev 1994, Coher 1995). The known extant species have been exhaustively studied, the male terminalia of all species have been illustrated (Bechev 1990, Zaitzev 1994, Coher 1995). All but one of the species have either a Palaearctic or a Nearctic distribution, while a single species is recorded from the temperate Nepal in the Oriental region (Bechev 1990). Three species are known to occur in Europe: the widely distributed Anaclileia dispar (Winnertz, 1863) and A. dziedzickii (Landrock, 1911), and A. beshovskii Bechev, 1990 which is known only from Bulgaria, Switzerland and the Czech Republic (its occurrence in Sweden according to Chandler (2013) is an error as the species was removed from the Swedish checklist already by Kjærandsen et al. (2007a)).

In Transcaucasia (i.e. Republics of Armenia, Azerbaijan and Georgia), sciaroid fungus gnats including mycetophilids are still rather poorly studied. There are 21 species of Mycetophilidae reported from Azerbaijan (Zaitzev 1994, 2003) and five species from Armenia (Joost \& Plassmann 1985, Zaitzev 1994). Surprisingly, no species was reported from Georgia until Kurina 


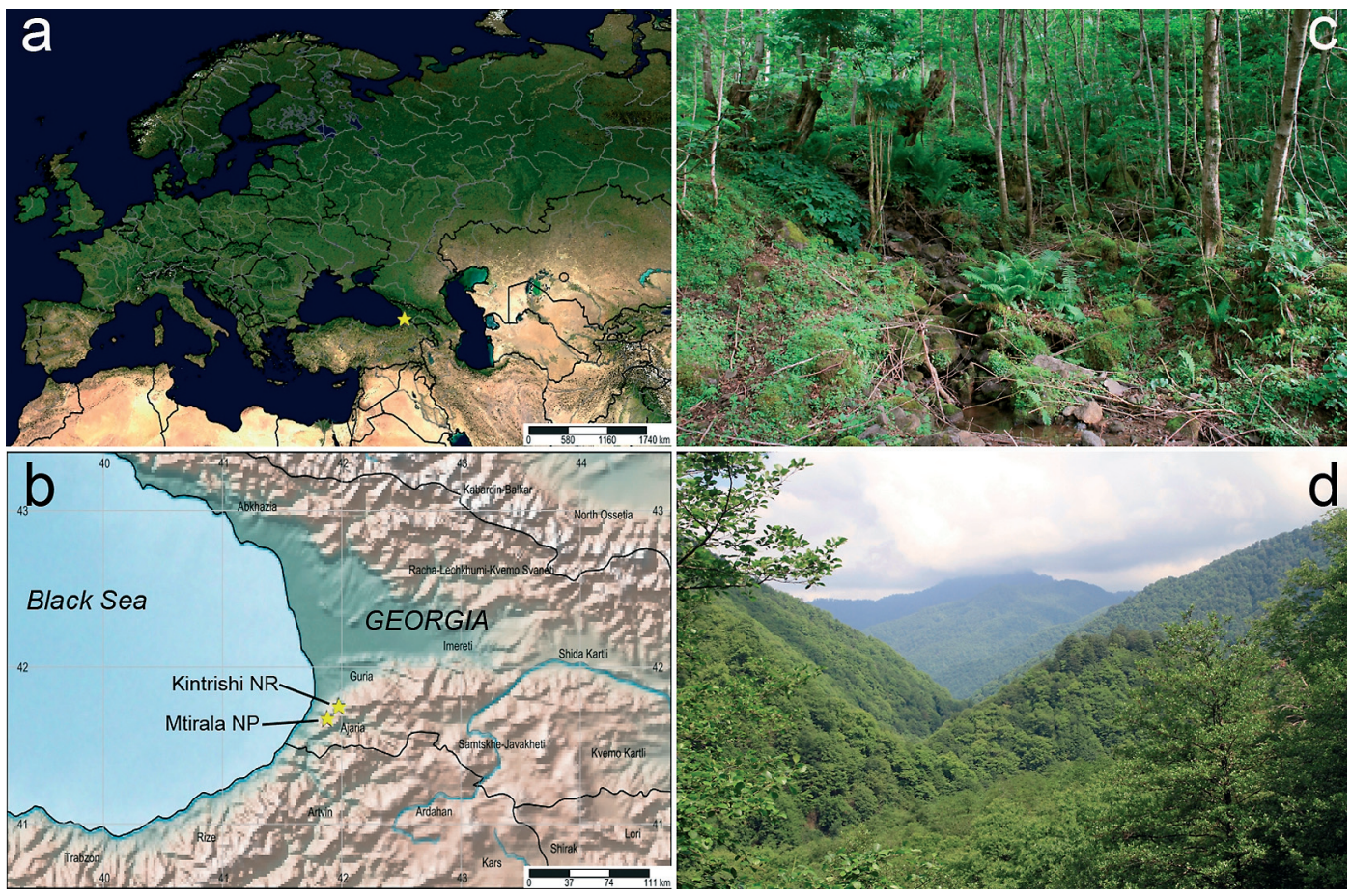

Fig. 1. - a, b. Sampling localities of Anaclileia adjarica sp. n. in southwestern Georgia. - c, d. The localities are characterized by the Colchic broad-leaved forests: Mtirala NP (c) and Kintrishi NR (d).

(2014) mentioned 149 species but without any additional data on species composition. Subsequently, Jürgenstein et al. (2015) and Kurina et al. (2015) provided data on three and one species, respectively. These studies did not record any Anaclileia species from the region.

While studying fungus gnat material from Georgia, an unusual Anaclileia species was found and identified as a species new to science. The aim of this paper is to describe and discuss it.

\section{Materials and methods}

The studied fungus gnat material was collected in 2013 by sweep netting and light trapping from two localities in Georgia (Fig. 1a, b): surroundings of the visitor centres of Mtirala NP and Kintrishi NR, both northeast of Batumi on the western slopes of the Meskheti Range of the Lesser Caucasus. All the collecting was carried out in habitats lower than $500 \mathrm{~m}$ a.s.l., characterized by pristine Colchic humid broad-leaved forests dominated by Castanea sativa Mill., Fagus orientalis Lipsky, Carpinus caucasica Grossh.,
Quercus pontica K. Koch and Tilia dasystyla Steven (Fig. 1c, d). The area is noted for the extraordinarily high annual precipitation, with an average over 2,000 $\mathrm{mm}$ but exceeding 4,000 $\mathrm{mm}$ on the seaside slopes of Mountain Didi Mtirala (e.g. Murvanidze et al. 2016).

All specimens were initially preserved in $70 \%$ ethyl alcohol. After the examination, some of the specimens were mounted from alcohol, using a chemical method described by Vockeroth (1966), and double-mounted using minute pins. For detailed study and illustration of the terminalia, these were detached and treated by the method described by Kjærandsen et al. (2007b). After the examination, the terminalia were stored in glycerine in a separate plastic microvial attached to the same pin as the mounted specimen. For the detailed morphological study, a few permanent slides were also prepared. For this process, the wings were detached and mounted under a coverslip in Euparal medium. Thereafter, the rest of the body including terminalia was macerated in warm concentrated potassium hydroxide $(\mathrm{KOH})$, followed by washing in distilled water and dehydrating in stages of increasing concen- 
Fig. 2. Anaclileia adjarica sp. n. (holotype). - a. Habitus. - b. Close view of head and thorax. -c. Close view of male terminalia.

Abbreviations: abd, abdomen; anepst, anepisternum; aprnt, antepronotum; cx, coxa; gc, gonocoxite; hlt, haltere; Itg, laterotergite; mtepst, metepisternum; $\mathrm{mtg}$, mediotergite; oc, ocellus; ped, pedicel; plp, palpal segment; preepst, preepisternum; proepst, proepisternum; sc, scutum; scp, scape; tg, tergite; vrt, vertex; wg, wing. Scale bars 1 $\mathrm{mm}(\mathrm{a})$ and 0.2 $\mathrm{mm}(\mathrm{b}, \mathrm{c})$.

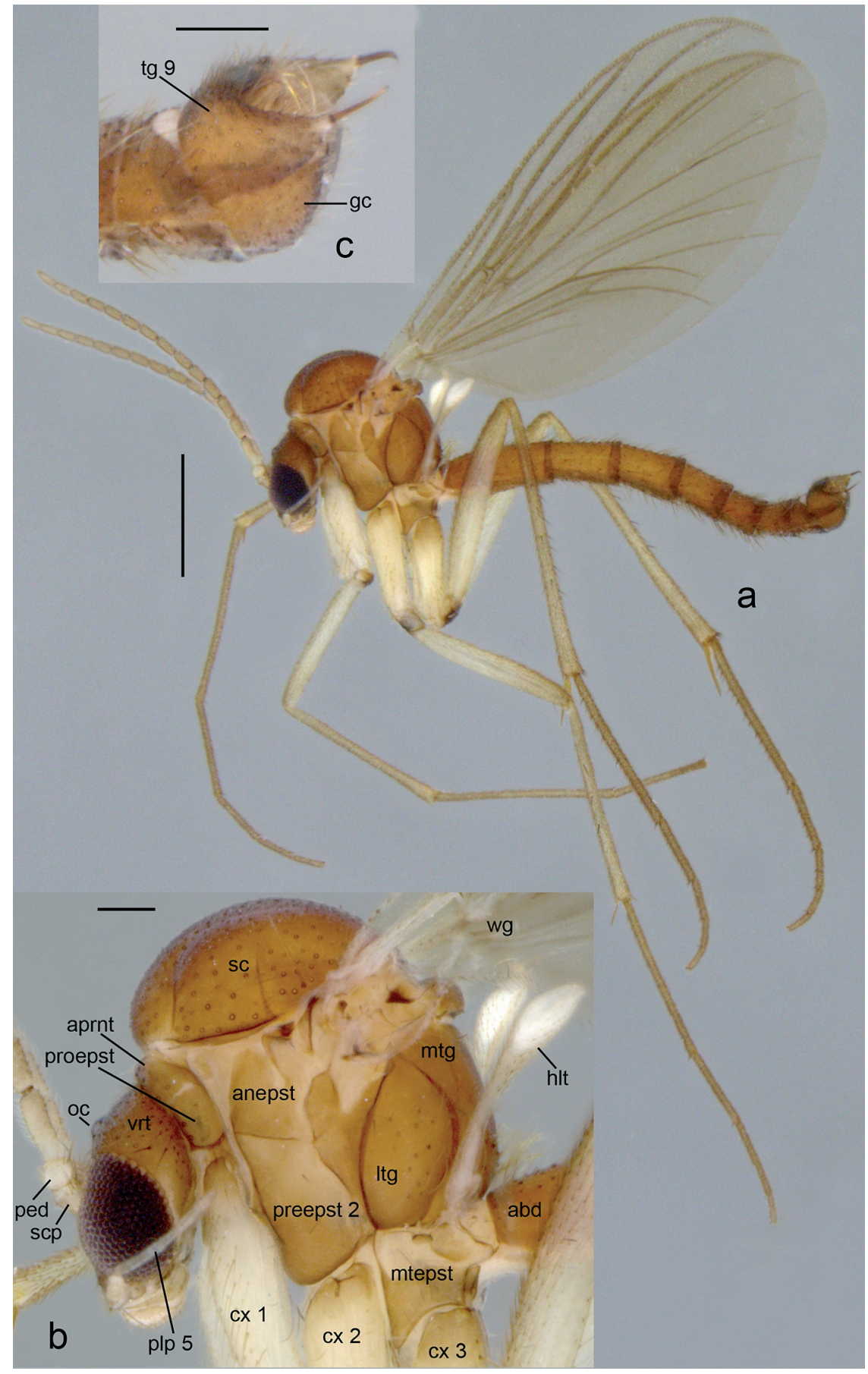

tration of ethyl alcohol. Parts of the body and the terminalia were then mounted separately between two coverslips in Euparal medium and attached to the same slide using stripes of adhesive tape (see also Hippa \& Kurina 2012). The method of pres- ervation of each specimen is given in the type material section.

Illustrations of the terminalia were prepared using a U-DA drawing tube attached to a compound microscope Olympus CX31. The digital 


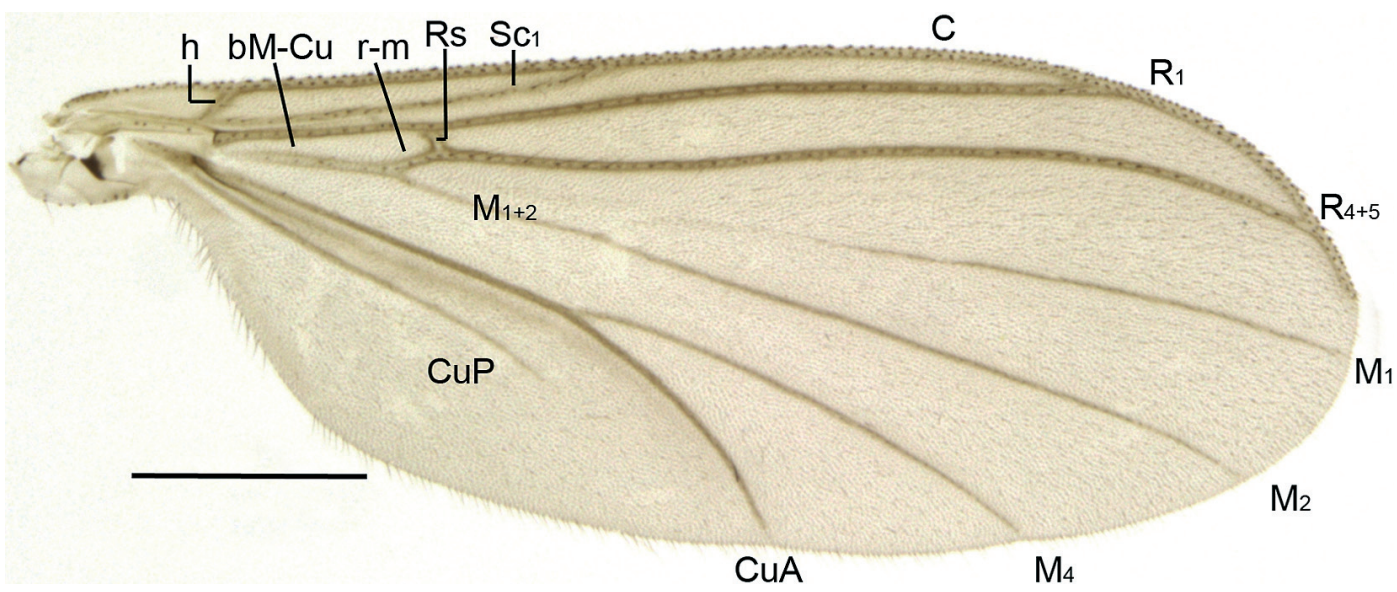

Fig. 3. Anaclileia adjarica sp. n. (paratype), wing. Scale bar $0.5 \mathrm{~mm}$.

images of general habitus, head, thorax and terminalia were combined using the software LAS V.4.1.0. from multiple gradually focused images taken by a Leica DFC 450 camera attached to a Leica 205C stereomicroscope or Leica DM 6000 B compound microscope, respectively (see also Kurina et al. 2015). Adobe Photoshop CS5 was used for editing the figures and compiling the plates.

Morphological terminology follows generally that of Søli (1997) while for the interpretation of the wing venation Søli (2017) was used. The measurements are from the specimens in alcohol and are given as the range of measured specimens followed by the mean value, while the measurements from the holotype are given in square brackets. The ratios of the three apical palpal segments are given as $3^{\text {rd }}: 4^{\text {th }}: 5^{\text {th }}$. All material is deposited in the insect collection in IZBE - Institute of Agricultural and Environmental Sciences, Estonian University of Life Sciences (former Institute of Zoology and Botany), Tartu, Estonia.

\section{Description of Anaclileia adjarica sp. n. Figs 2-5.}

Type material. Holotype: $\widehat{\jmath}$, GEORGIA, Mtirala $\mathrm{NP}$, near visitor centre, $41^{\circ} 40^{\prime} 38.9^{\prime} \mathrm{N} 041^{\circ} 51^{\prime}$ 18.2'E, alt. $240 \mathrm{~m}$, sweeping, 19.V.2013, O. Kurina leg. (in alcohol). Paratypes: $2 \hat{\jmath}$, same data as holotype ( $1 \delta$ in alcohol; 10 mounted from alcohol); $3 \widehat{\jmath} 3$ 우의, same data as holotype except

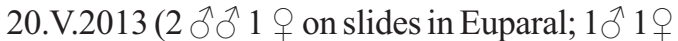

mounted from alcohol; 19 in alcohol); $1 \hat{0}$, same data as holotype except light trap (mounted from alcohol, terminalia in glycerine); $1 \hat{\jmath}$, GEORGIA, Kintrishi NP, 41 ${ }^{\circ} 45^{\prime} 11.7{ }^{\prime} \mathrm{N}$ 041 ${ }^{\circ} 58^{\prime}$ 38.4'E, alt. 453 m, sweeping, 22.V.2013, O. Kurina leg. (in alcohol).

Description. Male. Body length: 3.2-3.4, 3.3 [3.2] $\mathrm{mm}(n=4)$

Head (Fig. 2a-b): Brown to dark brown, with numerous setae. Three ocelli in a shallow and wide triangular arrangement, with laterals separated from eye margins by a distance about triple their own diameter. Face semicircular, with medial portion well convex, lower portion fused with conical clypeus, wider than high; both brown, setose. Mouthparts light brown. Palpus five segmented, yellowish-brown. Ratio of three apical palpal segments $1.0: 1.8-1.9,1.9$ [1.9] : 1.6-2.0, 1.8 [1.8]. Scape and pedicel light brown, pedicel somewhat lighter. Flagellum 14-segmented; flagellomeres light brown, with short pale setae; first flagellomere basally pale, elongated, about 3 times as long as broad apically; flagellomeres 2-13 cylindrical; fourth flagellomere 2.1-2.5 times as long as broad; apical flagellomere slightly conical, 3.3-3.8 times as long as broad at base.

Thorax (Fig. 2a-b): All parts brown, all setae yellow to brownish. Mesonotum with evenly arranged numerous setae. Scutellum with 14-22 setae dorsally, not arranged in distinct pairs along the margin. Antepronotum with 7-9 and proepisternum with 3-6 setae of unequal size, laterotergite with 7-12 setae and mediotergite with 12 


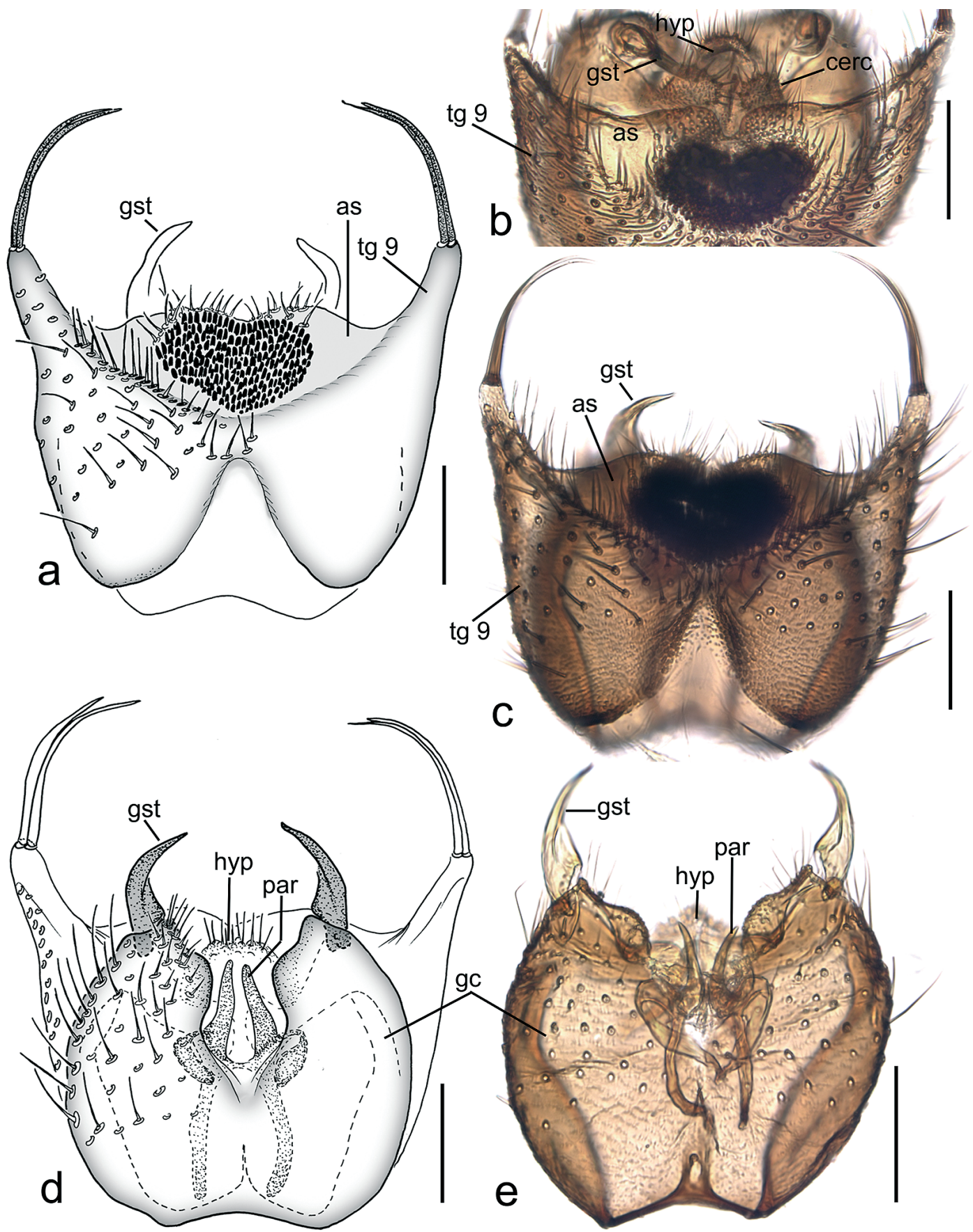

Fig. 4. Anaclileia adjarica sp. n. (paratype), male Terminalia. - a, c. Dorsal view. - b. Posterior view. - d, e. Ventral view. Abbreviations: as, apical shelf of tergite 9; cerc, cercus; gc, gonocoxite; gst, gonostylus; hyp, hypoproct; par, paramere; tg, tergite. Scale bars $0.1 \mathrm{~mm}$.

16 setae medially on lower part. Other pleural parts bare. Haltere yellow with pale knob, setose.

Legs (Fig. 2a). All coxae yellow, basally slightly infuscated. All trochanters brown. All femora and tibiae yellow, femora apically slightly infuscated, tarsi appearing darker because of dense setae. Fore tibia without diverging setae. Mid tibia with 2-3 anterior and 0-2 dorsal setae. 


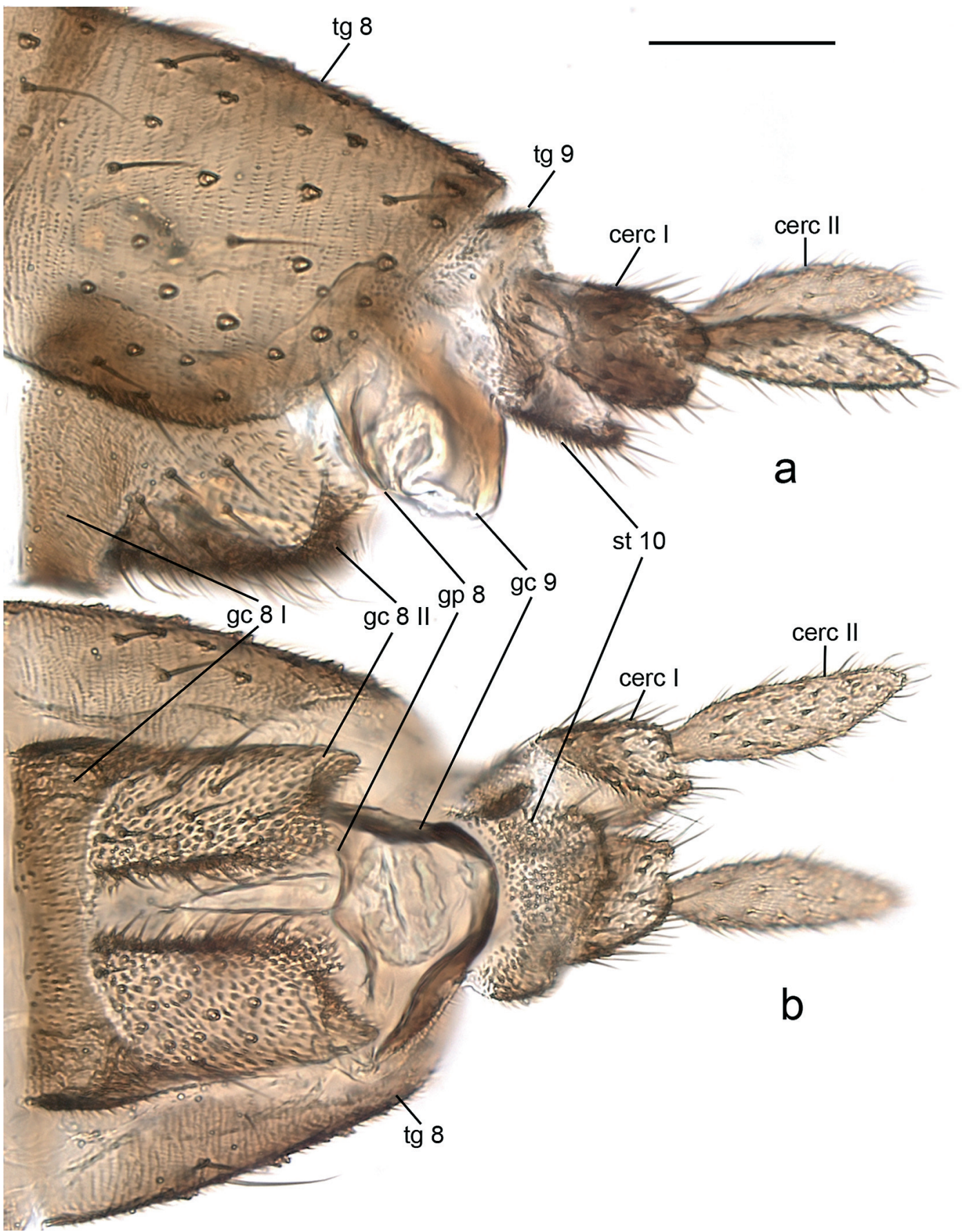

Fig. 5. Anaclileia adjarica sp. n. (paratype), female Terminalia. - a. Lateral view. - b. Ventral view. Abbreviations: cerc, cercus; gp, gonapophysis; gc, gonocoxite; st, sternite; tg, tergite. Scale bar $0.1 \mathrm{~mm}$.

Hind tibia with 3-4 anterior, 1-4 antero-dorsal, 4-7 dorsal and 0-3 posterior setae, and with a postero-apical sparse comb of setae. Ratio of femur to tibia for fore-, mid- and hind legs: 0.74
$0.83,0.79$ [0.83]; 0.80-0.89, 0.85 [0.85]; 0.76$0.88,0.80$ [0.88]. Ratio of tibia to basitarsus for fore-, mid- and hind legs: 1.04-1.13, 1.10 [1.10]; $1.15-1.31,1.25[1.31] ; 1.61-1.65,1.63$ [1.65]. 
Wing (Fig. 3). Hyaline, length 2.6-3.1, 2.8 [2.6] $\mathrm{mm}(n=4)$. All veins brown, costal and radial veins somewhat darker. Both surfaces of costal and radial veins setose, other veins setose only dorsally. Wing membrane with micro- and macrotrichia on both surfaces. Costa reaching halfway from $R_{4+5}$ to $M_{1}$. Sc reaching costa at about one quarter to one third between Rs and tip of $\mathrm{R}_{1} \cdot \mathrm{R}_{4+5}$ slightly sinuate. Crossvein $\mathrm{r}-\mathrm{m}$ about three times as long as Rs. $\mathrm{M}_{1}$ basally obsolete: observable vein beginning distally from middle of $\mathrm{R}_{1}$. Cubital fork beginning at the level of the apex of Sc or somewhat proximally.

Abdomen (Fig. 2a): First segment brown, IIIV segments yellowish to light brown, remaining segments brown to dark brown. Sternites somewhat lighter than tergites. Terminalia (Fig. 2c, 4a-e) brown to dark brown. Tergite 9 remarkably emarginated with protruding lateral portions, each bearing two simple and pointed megasetae. Apical shelf of tergite 9 with a wavy posterior margin with a U-shaped medial incision discernible in posterior view, and a heart-shaped aggregation of small spines medially. Anterior margin of tergite 9 with a deep incision medially. Setae on tergite 9 similar to those on gonocoxite. Cerci small, rounded, in dorsal view covered by tergite 9. Gonocoxite rounded, entirely covered by tergite 9 dorsally. Ventral medial margin of gonocoxite medially bulging, posteriorly forming an acute angle with lateral margin. Gonostylus simple, one-lobed, curved and apically pointed, with a sub-basal heel-like medial protrusion. Parameres tapering, posteriorly reaching the level of medial bulge of ventral medial margin of gonocoxite.

Female. Body length 2.9-3.0, 3.0 mm $(n=3)$. Wing length 2.7-2.9, 2.8. Colour and setosity similar to male. Terminalia (Fig. 5) brown. Cercus two-segmented: apical segment, elongated, more than three times as long as wide medially; basal segment sub-quadrate, about half as long as apical segment. Tergite 8 slightly longer than wide, anterior margin oblique in lateral view. Both tergite 9 and sternite 10 partly membraneous, more sclerotized medially. Gonapophysis 9 massive, in ventral view subtrapezoidal, with sclerotized lateral portions, well discernible in ventral view. Gonapophysis 8 as a rim anteriorly from gonocoxite 9 . Gonocoxite 8 with two ven- trally well separated sections: first section medially fused, short and apically concave; second section medially separated, both halves with an apical excision.

Biology. Unknown.

Etymology. The specific epithet refers to the type location in the Autonomous Republic of Adjara, Georgia.

\section{Discussion}

Using the generic key by Søli et al. (2000), the new species runs to Anaclileia and agrees perfectly with the generic diagnosis provided by Borkent and Wheeler (2013). The general structure of the male terminalia, especially that of gonocoxite and gonostylus, resembles species already described (cf. figures by Bechev 1990, Coher 1995). All species have the gonostylus one-lobed and bent medially, and the gonocoxite ventrally with lateral portions drawn out posteriorly. However, within the generic limits, $A$. adjarica sp. n. is unique by the peculiar outline and vestiture of tergite 9 which is 1 ) well emarginated with two simple megasetae apically on lateral portions of both sides (without megasetae in the case of the other species), 2) with a heart-shaped aggregation of small spines on the apical shelf (without an aggregation of spines in the other species), and 3) with a deep anterior incision (at most shallowly concave in the other species).

The discovery of a new Mycetophilidae species in Transcaucasia is not surprising. The family is extremely superficially studied in the area and in the Caucasus generally, which in addition to being a glacial refugium during the Pleistocene (e.g. Hewitt 1999) is also considered to be one of the biodiversity hotspots (e.g. Williams 2004). Anaclileia adjarica $\mathbf{s p .} \mathbf{n}$. is currently recorded only from the western slopes of the Lesser Caucasus but it could probably have a wider distribution along the north-facing slopes of the Pontic (Parhar) Mountains in Turkey. A possible more northern distribution beyond the Caucasus is unlikely as the Greater Caucasus Mts form a significant biological barrier (e.g. Seddon et al. 2002). However, further studies including extensive sampling would be necessary for any definitive conclusions. 
Acknowledgements. The study was funded by institutional research funding (IUT21-1) from the Estonian Ministry of Education and Research. I am grateful to Prof. T. Tammaru (Tartu, Estonia) for organising the collecting trip to Georgia in May 2013, and to Prof. G. Japoshvili (Tbilisi, Georgia) for assistance during the fieldwork in Georgia. Dr. J. Salmela (Rovaniemi, Finland), Dr. A. Polevoi (Petrozavodsk, Russia) and Dr. J. Ševčík (Ostrava, the Czech Republic) are thanked for their comments. Dr. A. Pont (Oxford, UK) kindly checked the English language.

\section{References}

Bechev, D. 1990: Recent Holarctic species of the genus Anaclileia Meunier (Insecta, Diptera: Mycetophilidae). - Reichenbachia 28: 67-71.

Borkent, C. J. \& Wheeler, T. A. 2013: Phylogeny of the tribe Sciophilini (Diptera: Mycetophilidae: Sciophilinae). - Systematic Entomology 38: 407-427. doi:10.1111/syen.12002

Chandler, P. J. 2013: Fauna Europaea: Bolitophilidae, Keroplatidae, Mycetophilidae. - In: Pape T. \& Beuk, P. (ed.), Fauna Europaea, Diptera. Fauna Europaea version 2.6.2. http://www.faunaeur.org. (accessed 2 October, 2017.)

Coher, E. I. 1995: A contribution to the study of the genus Anacliliea [Anaclileia] (Diptera: Mycetophilidae). Entomological News 106: 257-262.

Hewitt, G. M. 1999: Post-glacial re-colonization of European biota. - Biological Journal of the Linnean Society $68: 87-112$.

Hippa, H. \& Kurina, O. 2012: New species and new records of Afrotropical Manota Williston (Diptera, Mycetophilidae), with a key to the species. - Zootaxa 3455: 1-48.

Joost, W. \& Plassmann, E. 1985: Pilzmücken aus dem Kaukasus-Gebiet (UdSSR) (Insecta, Diptera, Mycetophilidae). - Faunistische Abhandlungen 12: 137139.

Jürgenstein, S., Kurina, O. \& Põldmaa, K. 2015: The Mycetophila ruficollis Meigen (Diptera, Mycetophilidae) group in Europe: elucidating species delimitation with COI and ITS2 sequence data. - ZooKeys 508: 15-51. doi: 10.3897/zookeys.508.9814

Kjærandsen, J., Hedmark, K., Kurina, O., Polevoi, A., Økland, B. \& Götmark, F. 2007a: Annotated checklist of fungus gnats from Sweden (Diptera: Bolitophilidae, Diadocidiidae, Ditomyiidae, Keroplatidae and Mycetophilidae). - Insect Systematics \& Evolution. Supplement 65: 1-128.

Kjærandsen, J., Kurina, O. \& Ólafsson, E. 2007b: The fungus gnats of Iceland (Diptera, Keroplatidae \& Mycetophilidae). - Insect Systematics \& Evolution. Supplement 64: 61-96.
Kurina, O. 2014: A faunistic account of selected bibionomorph families in Georgia. - In: Dorchin, N., Kotrba, M., Mengual, X. \& Menzel, F. (eds), $8^{\text {th }}$ International Congress of Dipterology, Abstract Volume: 191. Ampyx-Verlag, Halle (Saale). 440 pp.

Kurina, O., Õunap, E. \& Põldmaa, K. 2015: Two new Neuratelia Rondani (Diptera: Mycetophilidae) species from Western Palaearctic: a case of limited congruence between morphology and DNA sequence data. ZooKeys 496: 105-129. doi:10.3897/zookeys.496. 9315

Murvanidze, M., Mumladze, L., Arabuli, T., Barjadze, S. \& Salakaia, M. 2016: Oribatida diversity in different microhabitats of Mtirala National Park. - Journal of the Acarological Society of Japan 25(S1): 35-49.

Rindal, E., Søli, G. E. E. \& Bachmann, L. 2009: Molecular phylogeny of the fungus gnat family Mycetophilidae (Diptera, Mycetophiliformia). — Systematic Entomology 34: 524-532.

Seddon, J. M., Santucci, F., Reeve, N. \& Hewitt, G. M. 2002: Caucasus Mountains divide postulated postglacial colonization routes in the white-breasted hedgehog, Erinaceus concolor. - Journal of Evolutionary Biology15: 463-467.

Søli, G. E. E. 1997: The adult morphology of Mycetophilidae (s. str.), with a tentative phylogeny of the family (Diptera, Sciaroidea). — Entomologica Scandinavica Supplement 50: 5-55.

Søli, G. E. E. 2017: 20. Mycetophilidae (Fungus Gnats). In: Kirk-Spriggs, A. H. \& Sinclair, B. J. (eds), Manual of Afrotropical Diptera. Vol. 2 (Nematocera \& Lower Brachycera): 533-555. SANBI Publishing. 920 pp.

Søli, G. E. E., Vockeroth, J. R. \& Matile, L. 2000: A. 4. Families of Sciaroidea. - In: Papp, L. \& Darvas, B. (eds), Contributions to a Manual of Palaearctic Diptera. Appendix: 49-92. Science Herald, Budapest. 604 pp.

Ševčík, J., Kaspřák, D., Mantič, M., Fitzgerald, S., Ševčíková, T., Tóthová, A. \& Jaschhof, M. 2016: Molecular phylogeny of the megadiverse insect infraorder Bibionomorpha sensu lato (Diptera). — PeerJ 4:e2563. doi:10.7717/peerj. 2563.

Vockeroth, J. R. 1966: A method of mounting insects from alcohol. — The Canadian Entomologist 98: 69-70.

Williams, L. (ed.) 2004: Caucasus Biodiversity Hotspot. Briefing Book. Conservation International, $98 \mathrm{pp}$. http://www.cepf.net/Documents/final.caucasus.briefingbook.pdf. (accessed 16 October 2017.)

Zaitzev, A. I. 1994: Fungus gnats of the fauna of Russia and adjacent regions. Part I. Nauka, Moscow, 288pp. [In Russian, with English summary.]

Zaitzev, A. I. 2003: Fungus gnats (Diptera, Sciaroidea) of the fauna of Russia and adjacent regions. Part II. - An International Journal of Dipterological Research 14: 77-386. 